\title{
CHROMOSOME BREAKAGE IN YEAST CAUSED BY SISTER-CHROMATID RECOMBINATION IN AN INTEGRATED 2-MICRON PLASMID
}

\author{
by \\ STEEN HOLMBERG, TORSTEN NILSSON-TILLGREN ${ }^{1}$, \\ MORTEN C. KIELLAND-BRANDT \\ and \\ JENS G. LITSKE PETERSEN \\ Department of Physiology, Carlsberg Laboratory \\ Gamle Carlsberg Vej 10, DK-2500 Copenhagen Valby \\ and \\ 'Institute of Genetics, University of Copenhagen \\ Oster Farimagsgade 2A, DK-1353 Copenhagen K
}

Keywords: Saccharomyces cerevisiae, sister chromatid exchange, FLP, acentric fragment, dicentric fragment, chromosome breakage, double-strand break, DNA repair

\begin{abstract}
A pure yeast plasmid consisting of 2-micron DNA and a $9.4 \mathrm{~kb}$ fragment with HIS4 has been chromosomally integrated at the his4 locus in a haploid his4-24 strain. The integration was induced with sodium azide, whereafter colonies were screened for improved maintenance of histidine prototrophy. DNA was prepared from a strain with partially stabilized histidine prototrophy, and restriction fragments containing $H I S 4$ sequences were analysed. The results were consistent with the notion that the plasmid had integrated by homologous recombination.

Size-selected BamHI restriction fragments from the strain with the integrated plasmid were cloned in Escherichia coli. The clones were screened by colony hybridization and the plasmid from one clone which contained 2micron DNA sequences as well as HIS4 sequences was mapped. The structure of the insert showed that it was derived from the acentric fragment which is formed when an unequal sister-chromatid recombination occurs between the inverted repeats of the integrated 2-micron DNA. We suggest that this rearrangement frequently takes place, a hypothesis which was supported by the finding of a high rate of lethality in the culture.

This hypothesis was further confirmed by analysis of the genetic consequences of the rearrangement in a diploid. The results show that monocentric fragments are formed by breakage of the dicentric fragment during mitosis. The monocentric fragments are frequently lost, but are also often repaired by recombination or by resynthesis of the missing part of the chromosome, using the homologous chromosome III as a template.

Although some replication and disjunction of the acentric fragment appears to take place, we were able to maintain it by selection only for a limited number of generations.
\end{abstract}

Abbreviations: $\mathbf{N M}=$ non-mater; $\mathbf{k b}=$ kilobase

0105-1938/82/0047/0355/\$03.00 


\section{INTRODUCTION}

Two-micron DNA is a circular, doublestranded DNA species occurring widely in Saccharomyces strains, with about 50 copies per cell. Its molecular biology has been recently reviewed by BROACH (2). Because of its non-mendelian inheritance 2-micron DNA is called a plasmid, although both genetic $(22,32)$ and biochemical $(25,31,37)$ evidence suggests that it resides in the nucleoplasm. It has a size of six thousand base pairs and its most prominent structural feature is a non-tandem inverted repetition of six hundred base pairs, which subdivides the rest of the plasmid into two unique regions. Intramolecular recombination, promoted by the plasmid-coded gene $F L P$, frequently takes place between the two repeated regions. Due to this recombination the wild type plasmid is present in the yeast in equal amounts of two interconvertible forms that differ in the orientation of one unique region with respect to the other. The recombination occurs at a specific site within the repeated region. Two-micron DNA does not have nucleotide sequence homology with the chromosomes at levels detectable by molecular hybridization (4) and the natural plasmid has never been observed to integrate into the chromosomes.

Two-micron DNA or subsegments carrying its origin of replication are widely used as parts of genetic vectors, since they enable the vector to replicate autonomously in yeast.

During experiments on the transformation of yeast without the use of bacterial plasmids (20) we observed a meiotically induced integration of a plasmid consisting of a full copy of 2-micron DNA with a $9.4 \mathrm{~kb}$ PstI insert carrying the HIS4 gene. This integration was due to homologous recombination between sequences of the $9.4 \mathrm{~kb}$ PstI fragment and the chromosomal sequences at his4.

The original clone from this spore was lost (21), but rather than trying to obtain another occasional meiotically induced integration of the plasmid, we applied recombinogenic treatment in order to induce the integration in vegetative cells. An unstable chromosome with integrated 2-micron DNA was obtained and the nature of this instability is the subject of the present paper. Parts of the results have been reported previously in a summarized form (21).

\section{MATERIALS AND METHODS}

\subsection{Media and growth}

The media used for growth of yeast have been described (20). Escherichia coli was grown in LB ( $1 \%$ tryptone, $0.5 \%$ yeast extract, $1 \%$ sodium chloride, $0.1 \%$ glucose). Plates were solidified with $2 \%$ agar. Ampicillin (Sigma) was used at a concentraion of $50 \mu \mathrm{g} \cdot \mathrm{ml}^{-1}$. Growth of $\mathrm{E}$. coli was at $37^{\circ} \mathrm{C}$, except when the strain contained a plasmid derived from the thermosensitive vector pJC75-58, in which case $30^{\circ} \mathrm{C}$ or $20^{\circ} \mathrm{C}$ were used.

\subsection{Plasmids, strains and crosses}

The following plasmids were used: pJC75-58 (6); $\mathrm{pHHl}$, which is pBR322 with a full copy of 2-micron DNA inserted in the PstI site, was obtained from H. HartmanN and J. Collins; pC500 and pC502 (17). Yeast strains employed are given in Table I. The E. coli strain used was HB101. Crosses and tetrad analysis were carried out according to HAWTHORNE and MORTIMER (14). The two his4 mutant alleles his4-24 and his4-644 were distinguished by their different complementation behavior (10) when mated to strains carrying the his $4 C$ allele his4-280.

\subsection{Induction of plasmid integration with sodium azide}

The procedure of NILSSON-TILLGREN and KAHN (26) was used: Yeast cells grown to early stationary phase in YPD were washed three times in distilled water and resuspended in $0.1 \mathrm{M}$ sodium citrate $\mathrm{pH} 4.75$. Sodium azide was added to a final concentration of $50 \mathrm{~mm}$. The cell suspension was shaken in a closed screw-cap tube for 18 hours at $25^{\circ} \mathrm{C}$. The treatment was stopped by adding one tenth volume of $1 \mathrm{M}$-sodium citrate. Before plating, the cells were washed three times in distilled water.

\subsection{DNA purification}

The preparation of total yeast DNA (20) and plasmid DNA from E. coli $(17,19,38)$ has been described.

\subsection{Transformation}

The procedures for transformation of yeast (15) and E. coli (5) have been described. 
Table I

Yeast strains used in this study

\begin{tabular}{lll}
\hline Name & Genotype & Source \\
\hline C75-M23 & MAT $\alpha$ ade2 his4-24 & Genetic crosses (20) \\
C78-H23/1 & MAT $\alpha$ ade2 his4-24 [pC504:HIS4] & $(20)$ \\
C79-S976 & Stabilized derivative of C78-H23/1 & This study \\
C79-993 & MATa his4-644 leu2 thr4 ura4 & Genetic crosses (27) \\
C82-1799 & MAT $\alpha$ his4-29 leu2 thr4 trp1 arg4 & Genetic crosses \\
C79-917 & MATa his4-29 ura4 arg4-16 trp1 [TRP 1] & $(21)$ \\
\hline
\end{tabular}

2.6. In vitro packaging of DNA and transduction

In vitro packaging of ligated DNA into bacteriophage lambda particles and subsequent transduction into E. coli were performed according to Collins and HoHn (7). The biological activity of endogenous DNA in the packaging cell extract was destroyed by ultraviolet irradiation.

\subsection{Enzymes, electrophoresis and isolation of DNA fragments from agarose gels}

Restriction endonucleases, T4 DNA ligase and DNA polymerase I were purchased from Boehringer Mannheim Biochemicals and Bethesda Research Laboratories Inc. Gel electrophoresis of DNA (20) was in $0.4 \%$ or $0.7 \%$ agarose. Restriction fragments of specific sizes were purified from the agarose by gel electrophoresis into hydroxyapatite (36).

\subsection{Colony hybridization}

Colony hybridization was carried out according to GrunsteIn and Hogness (12) with the modifications described by BRANDT (1).

\subsection{In vitro labelling of DNA, transfer of electrophoretically separated DNA and hybridization}

Labelling of DNA by nick translation was performed as described by RigBY et al. (30), using ${ }^{32}$ P-dTTP (Amersham Radiochemical Centre or New England Nuclear). DNA fragments separated in agarose gels were transferred to nitrocellulose filters (Millipore, HAWP 000 10) by a modification of the procedure of SOUTHERN (33) as previously described (17). Hybridization of labelled DNA to the DNA immobilized on nitrocellulose was performed as described by DEN-
HARDT (8) with the modifications of JEFFREYS and Flavell (18). Autoradiographic exposure was for 0.5-72 hours with or without Kodak XOmatic intensifying screens at $-80^{\circ} \mathrm{C}$.

\subsection{Containment}

Experiments involving recombinant DNA were registered with the committee on genetic engineering of the Danish National Research Councils. Yeast cells containing DNA sequences from pJC75-58 were handled under P1 conditions and E. coli cells containing yeast DNA sequences were handled under $\mathrm{P} 2$ conditions (13).

\section{RESULTS}

\subsection{Recombinogenic treatment can induce partial stabilization of the unstable $\mathrm{His}^{+}$ phenotype associated with a 2 -micron DNA-HIS4 plasmid}

The plasmid pC504 was constructed by inserting a $9.4 \mathrm{~kb}$ chromosomal PstI fragment from S. cerevisiae with HIS4 into 2-micron DNA at the PstI site $(17,20)$. The plasmid is able to replicate autonomously in yeast, but is lost at a high rate during growth. Even under selective conditions only about a quarter of the cells have retained the plasmid. We have devised a simple plate test which is useful to distinguish colonies with this level of instability from colonies with a more stable prototrophic phenotype: After growth on a histidine-free plate a replica is made onto the complete medium YPD, and the fraction of histidine prototrophic cells in each unstable colony will decrease to a few per cent. Upon a subsequent replica plating from the YPD plate to a new histidine-free plate each unstable colony will give rise to a patch of non-growing cells with growing papillae, while a stable, prototrophic 
colony will show up by its confluent growth.

This plate assay was used to screen for stabilization of the $\mathrm{His}^{+}$phenotype after recombinogenic treatment of cells harboring the plasmid, pC504. As a recombinogen, sodium azide was chosen. When used as described in section 2.3 , it induces mitotic recombination in a diploid at a high rate without enhancing the reversion frequency of auxotrophic point mutations (26). Ten to the ninth cells of C78-H23/1 (MAT a ade2 his4-24 [pC504: HIS4]) were treated with sodium azide to a survival of $10 \%$ and subsequently grown over night in $5 \mathrm{ml}$ of liquid medium without histidine and a sample was plated to screen the colonies for stability as described above. Ten colonies with greatly enhanced stability were picked and tested further. Seven of the clones were completely stable histidine prototrophs and 3 segregated histidine auxotrophs at a low frequency: $3-20 \%$ during 7 generations of growth in YPD. These clones were hypothesized to be products of integration of pC504 at the his4 locus and one of them, C79-S976, was investigated further. The fully stabilized clones may be regarded as results of mitotic gene conversion.

\subsection{Restriction endonuclease analysis of the his4 region of the partly stabilized $\mathrm{His}^{+}$strain C79-\$976}

Chromosomal integration by homology of pC504 in C78-H23/1 will, if it takes place as a simple cross-over, yield the structure his 4 - 2-micron DNA - HIS4 or HIS4 - 2-micron DNA his4. Either of these two configurations would seem consistent with the level of segregation of His $^{-}$cells exhibited by strain C79-S976. The type of arrangement can be tested by restriction endonuclease analysis of DNA from the yeast, using the $9.4 \mathrm{~kb}$ HIS4 PstI fragment as hybridization probe.

Thus, total DNA was isolated from C79-S976. The culture was grown for about 30 generations in YPD and at the time of harvest a sample was plated on YPD for subsequent replication to histidine-free medium. Thirty-five per cent of the colony-forming units were $\mathrm{His}^{-}$. Four $\mathrm{His}^{+}$colonies on the YPD plate were picked, grown up in liquid YPD and plated again on YPD for subsequent replica plating as before. Two still had the partly stabilized phenotype of C79-S976, where- as the two others were completely stable. Thus the extracted DNA is from a population of roughly equal numbers of HIS4, his4 and partially stable $\mathrm{His}^{+}$cells.

Samples of this DNA were treated with restriction endonucleases EcoRI or BamHI, subjected to electrophoresis and the electropherogram was hybridized with ${ }^{32} \mathrm{P}$-labelled HIS4 DNA (pC502) and autoradiographed (Figure 1). As expected, bands characteristic for both HIS4 and the 500 bp deletion his4-24 were seen in C79S976 (EcoRI digestion, lane $h$ ). BamHI does not cut in the cloned $9.4 \mathrm{~kb}$ PstI fragment, but leaves this sequence on a fragment about $21 \mathrm{~kb}$ long when total wild-type yeast DNA is digested (lane e). Since BamHI neither cuts 2-micron DNA, the expected structure, HIS4 -2-micron DNA his4-24, for the partially stabilized cells, should be recognizable by hybridization with labelled HIS4 sequences as a larger fragment. Since 2micron DNA has a size of $6.3 \mathrm{~kb}$ the fragment should be $21-0.5+9.4+6.3$, i.e. about $36 \mathrm{~kb}$. Indeed a band of size $30-40 \mathrm{~kb}$ is seen, in addition to the band of about $21 \mathrm{~kb}$ (lane d).

\subsection{Molecular cloning and mapping of an extended chromosomal sequence linked to 2- micron DNA}

In order to investigate the detailed structure of the observed 30-40 kb BamHI fragment it was isolated by size fractionation and subsequent molecular cloning: Five hundred micrograms of DNA from C79-S976 were digested with restriction endonuclease BamHI and fractionated on $0.4 \%$ agarose gels. Fragments larger than $23 \mathrm{~kb}$ were ligated into cosmid pJC75-58 (6) employing a ratio of $2: 1(w / w)$ at a DNA concentration of $450 \mu \mathrm{g} \cdot \mathrm{ml}^{-1}$, after linearization of the cosmid with BamHI. Two micrograms of the ligated DNA were packaged in vitro into bacteriophage $\lambda$ particles and transduced into $E$. coli (7). Eighty-seven ampicillin resistant transductants were recovered. Colony hybridization with radioactive DNA probes showed that one of the transductants contained a plasmid with 2-micron DNA sequences as well as HIS4 sequences, while another colony contained HIS4 sequences only (Figure 2). The plasmid containing both 2-micron DNA and HIS4 sequences, called pC505, 


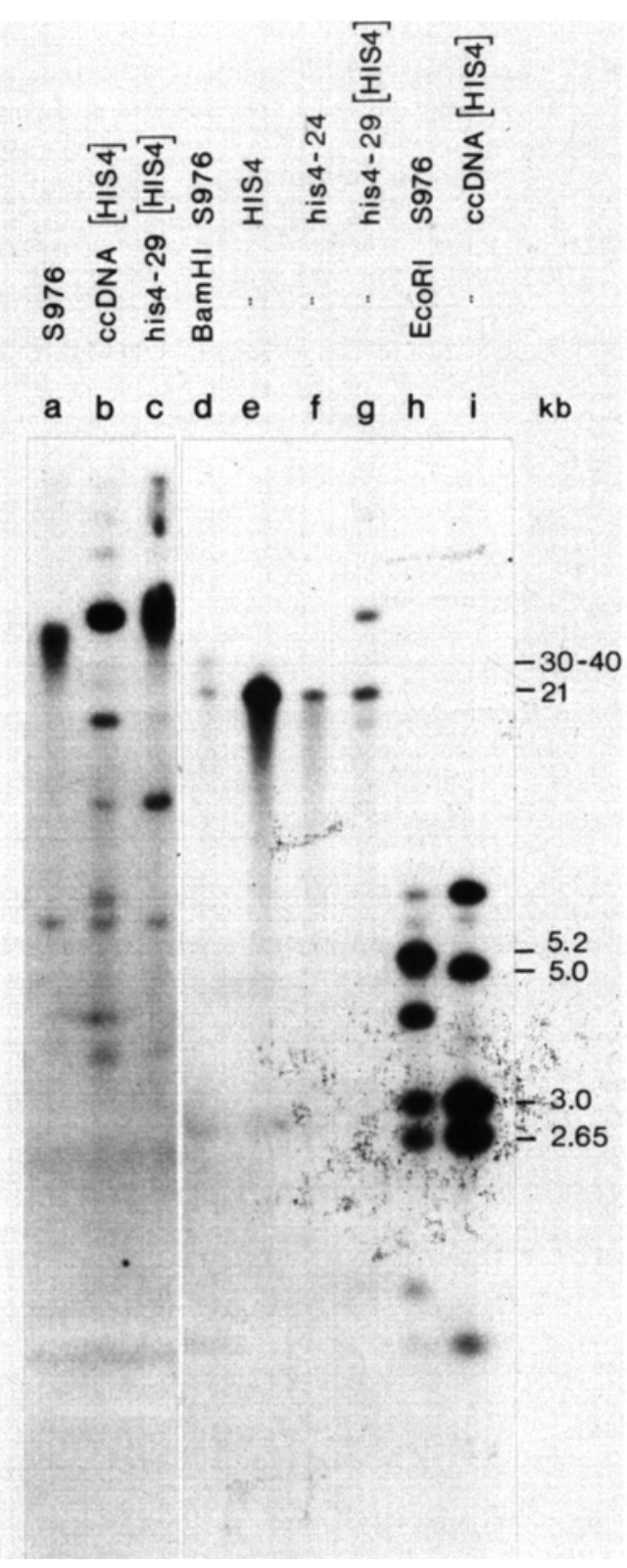

Figure 1. Detection and sizing of restriction endonuclease fragments carrying sequences belonging to the HIS4 Pstl fragment.

Total DNA from the partially stabilized strain C79S976 (lanes a, d, and h), transformant his 4-29 [pC505:HIS4] strain C78-H26 (lanes c and g), HIS4 strain S288C (lane e) and his4-24 strain C75-M23 (lane $\mathrm{f}$ ) as well as ccDNA from transformant $\mathrm{C} 78-\mathrm{H} 26$ (lanes $b$ and i) were treated with restriction endonucle- ases BamHI or EcoRI (lanes d-i) or left untreated (lanes a-c). After electrophoresis at $1.5 \mathrm{~V} \cdot \mathrm{cm}^{-1}$ in $0.4 \%$ agarose (origin at top), the specific sequences were detected by molecular hybridization and autoradiography (33). The radioactive hybridization probe was pC502, a bacterial plasmid carrying the HIS4 PstI fragment (17).

The 3.0 and $2.65 \mathrm{~kb}$ fragments in lanes $\mathrm{h}$ and $\mathrm{i}$ are characteristic for $H I S 4$ and the $5.2 \mathrm{~kb}$ fragment in lane $\mathrm{h}$ is characteristic for his4-24. The $21 \mathrm{~kb}$ band in lanes $\mathrm{d}-\mathrm{g}$ is the HIS4 BamHI fragment, whose mobility is not detectably affected by deletions up to $0.9 \mathrm{~kb}$. By electrophoresis at a higher agarose concentration HOLmBerg et al. (16) estimated the size of this fragment to about $16 \mathrm{~kb}$. For the identity of this and other bands cf. Holmberg et al. $(16,17)$.

The $30-40 \mathrm{~kb}$ band in lane $\mathrm{d}$ indicates a chromosomally integrated state of pC504 in the partially stabilized strain C79-S976. a

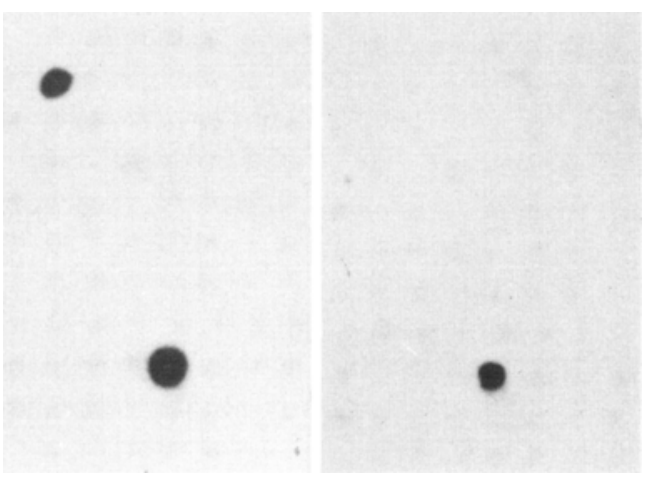

Figure 2. Screening of bacterial colonies, containing cosmids, for the presence of inserts with nucleotide sequences of the HIS4 PstI fragment (a) and 2-micron DNA (b).

${ }^{32} \mathrm{P}$-labelled probes of $\mathrm{pC502}(\mathrm{a})$ and $\mathrm{pHHl}$ (b) were hybridized to the DNA of the bacteria which had been lysed on nitrocellulose filters (12). was expected to contain an insert of the structure his4 - 2-micron DNA - HIS4. To confirm this, it was propagated, purified and mapped by restriction endonuclease cleavage. Figure 3 shows an ethidium bromide stained gel with fragments obtained using BamHI, PstI, EcoRI, SalI and HindIII, singly and in combinations. We were not able to interpret the band pattern on the basis of 


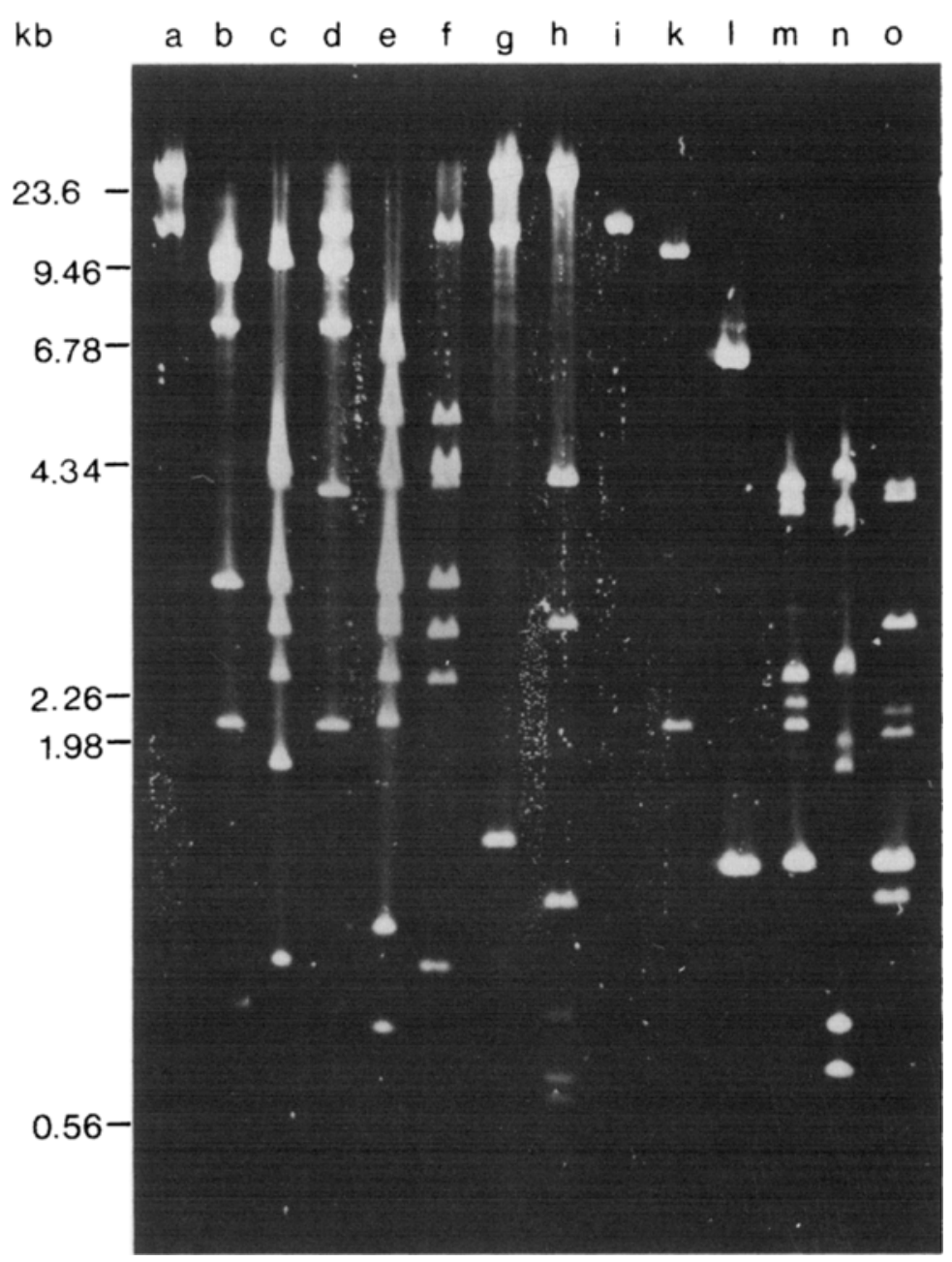

Figure 3. Restriction cleavage of plasmid pC505.

One half microgram samples of pC505 were treated with restriction endonucleases BamHI (lane a), BamHI+ PstI (lane b), BamHI + EcoRI (lane c), PstI (lane d), PstI + EcoRI (lane e), EcoRI (lane f), SalI (lane g) and HindIII (lane h). The cosmid vector, pC75-58, cleaved with BamHI (lane i) and PstI (lane k) was included. Finally are shown PstI (lane l), EcoRI (lane m), PstI + EcoRI (lane n) and HindIII (lane o) cleaved ccDNA from strain C79-917. This strain contains two sorts of 2-micron DNA, as apparent from lane $\mathrm{m}$. They correspond to those called Scp1 and $S c p 2$ by CAMERON et al. (4). The strong $1.45 \mathrm{~kb}$ band in lanes $1, \mathrm{~m}$ and $\mathrm{o}$ is due to the presence of a circularized TRPI EcoRI fragment (21) introduced by transformation. Electrophoresis was for 16 hours at 2 $\mathrm{V} \cdot \mathrm{cm}^{-1}$ in $0.7 \%$ agarose. 


\section{TABLE II}

Sizes and hybridization behavior of restriction fragments of pC505. The restriction fragment patterns are given in Figure 3 and have been used to construct the map of Figure 5.

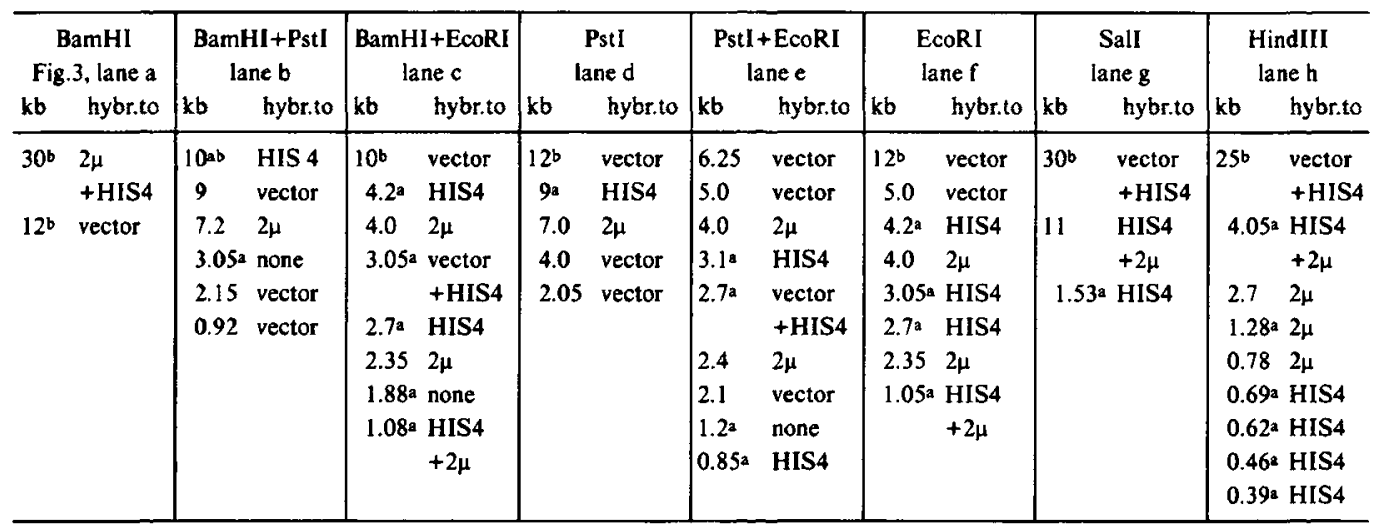

a Band intensity indicates that more than one fragment of this size is formed from each plasmid molecule.

b Approximate size.

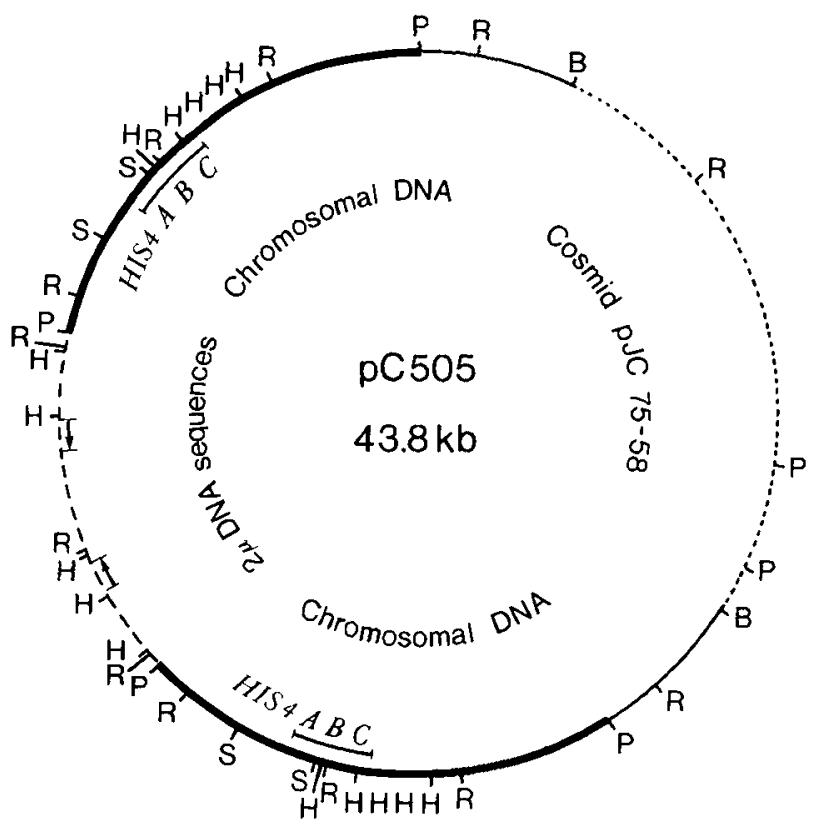

Figure 5. Cleavage map of $\mathrm{pC} 505$, derived from the data of Table II.

B, H, R, S and P designate cleavage sites for restriction endonucleases BamHI, HindIII, EcoRI, SalI and PstI, respectively. Arrows indicate position and orientation of the natural inverted repeat in 2-micron DNA. Continuous lines designate yeast chromosomal sequences; the thick lines sequences of the HIS4 PstI region. The broken line means 2-micron DNA and the dotted line shows where the sequence of cosmid pJC75-58 is. The orientation of this sequence has been chosen arbitrarily, as it could not be determined from the data. 


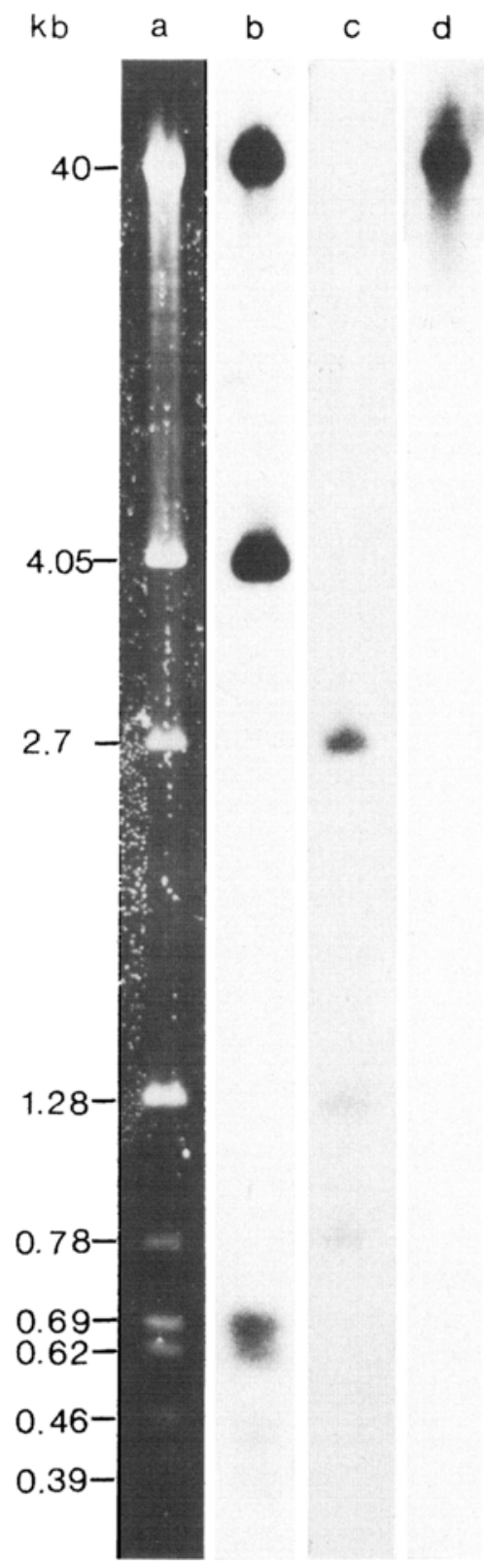

Figure 4. Determination of the origin of restriction endonuclease fragments of plasmid pC505.

Three gels identical to that shown in Figure 3 were set up. Molecular hybridization with ${ }^{32}$-labelled DNA probes (33) and subsequent autoradiography revealed the presence of specific sequences in each band. The lanes with the HindIII digest are shown. a: Staining with ethidium bromide. b: Hybridization with the HIS4 PstI fragment cut out from pC502 and purified. c: Hybridization with a full copy of 2-micron DNA cut out from $\mathrm{pHH} 1$ and purified. d: Hybridization with the cosmid vector $\mathrm{pJC} 75-58$. the assumption that the insert present in pC505 is the primary product of integration of pC504 at his4. It was therefore decided to hybridize identical electropherograms with each of the following probes: ${ }^{32} \mathrm{P}$-labelled DNA of the $9.4 \mathrm{~kb}$ PstI fragment containing HIS4, ${ }^{32} \mathrm{P}$-labelled pJC75-58 and ${ }^{32}$ P-labelled 2-micron DNA sequences. The origin of each band could then be determined and is given in Table II. As an example for the identification of the bands, the HindIII lane of the stained gel is presented together with the HindIII lanes of the autoradiograms for the three hybridizations in Figure 4.

The map of pC505 shown in Figure 5 could then be constructed. The cloned BamHI fragment does not have the structure of a primary product of chromosomal integration of pC504. It does have some of the expected features: Two regions with sequences corresponding to the HIS4 PstI fragment bracket a region of 2-micron DNA sequences and are flanked by regions hybridizing with neither 2-micron DNA nor the HIS4 PstI fragment. However, both HIS4 PstI regions carry the wild type allele, i.e. his4-24 is absent. Furthermore, the two non-hybridizing chromosomal regions have identical maps, which together with the HIS4 PstI regions and part of the 2-micron DNA sequences form an inverted repeat bracketing the rest of the 2-micron DNA. Thus, the 2-micron DNA sequence is not a simple copy of the plasmid. When pC504 was made, one of the unique regions of the 2-micron DNA was split into two parts by the insertion of the HIS4 PstI fragment $(17,20)$. In the cloned BamHI fragment (Figure 5) one of these two parts is present twice, being part of the large inverted repeat of $\mathrm{pC} 505$, whereas the other is missing. The other unique region is undisturbed and is the only sequence that has remained unique in the cloned BamHI fragment.

As might be expected, pC505 can transform yeast to histidine independence at the frequency characteristic of self-replicating plasmids.

\subsection{Sister-chromatid recombination involving integrated 2-micron DNA}

The sequence arrangement of the cloned BamHI fragment has evidently arisen by a recombinational event at the inverted repeat regions of 2-micron DNA linked to HIS4 se- 


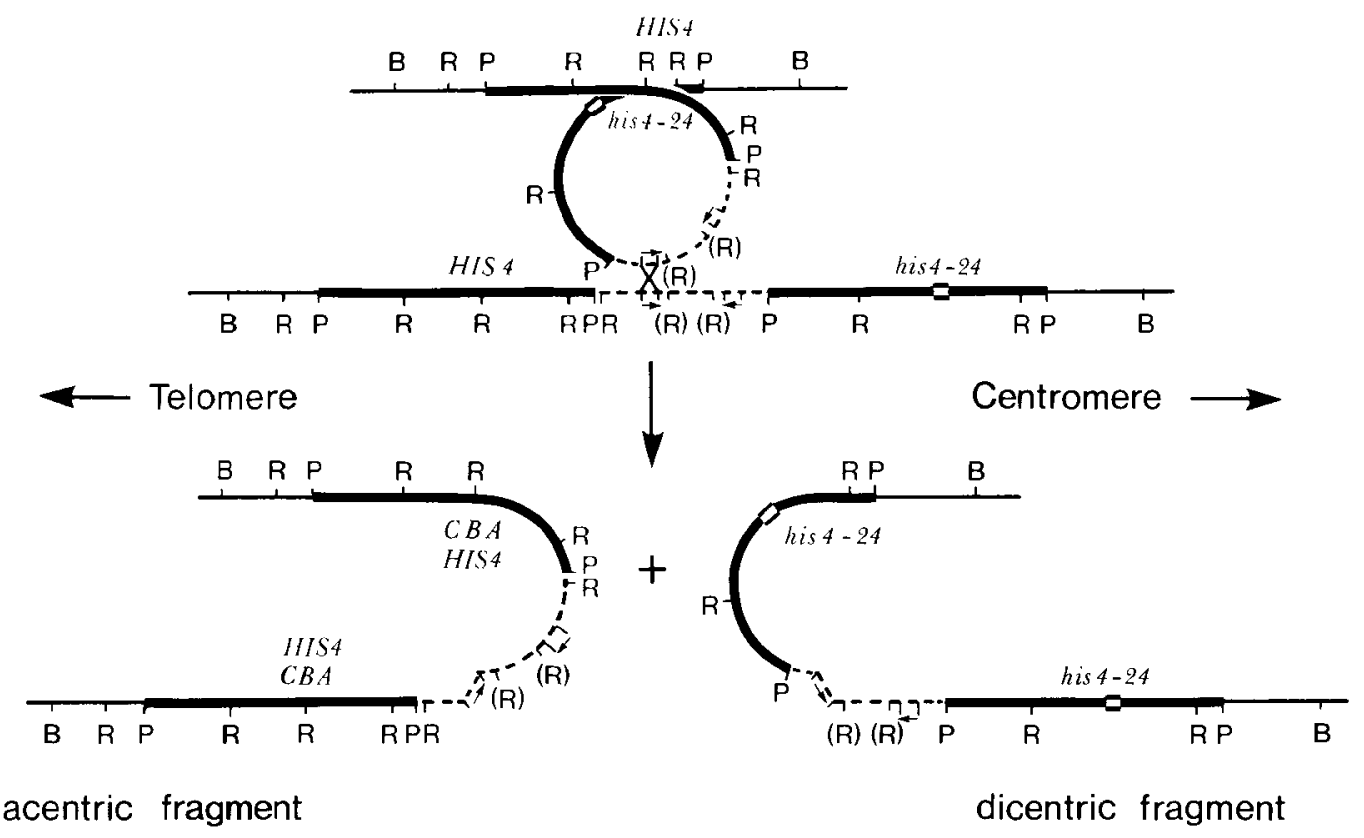

Figure 6. Mitotic sister-chromatid recombination involving integrated 2-micron DNA.

Some restriction endonuclease cleavage sites are shown and abbreviated as in Figure 5. (R) means one of the two possible positions for the EcoRI site in the invertible part of the 2-micron DNA sequences. The small arrows indicate position and orientation of the natural inverted repeat in 2-micron DNA. $C, B$ and $A$ designate the functional regions of the HIS4 gene. Thick line and broken line mean sequences of the HIS4 PstI region and of 2-micron DNA, respectively.

quences. It is extremely unlikely that this recombination should have taken place in E. coli. First, two different HIS4 -carrying cosmids would have to transduce the same cell and the multiplicity of transduction was low: Only two colonies with HIS4 sequences were obtained from $10^{9}$ cells. Secondly, recombination at the inverted repeat regions of a 2-micron DNA sequence is infrequent when they are in E. coli (cf. refs. 11,17). Rejecting this possibility we conclude that the cloned BamHI fragment was cut out from a molecule existing in the C79-S976 culture. We propose that this DNA molecule was an acentric fragment derived from chromosome III by the recombinational event shown in Figure 6 . The position of the EcoRI site in the repeated, nonhybridizing region of pC505 is identical to the position of an EcoRI site in the corresponding region adjacent to the HIS4 PstI region (16). This fact, as well as the absence from the nonhybridizing region of other cleavage sites for the used enzymes, is consistent with the identity of the two regions. Unfortunately, the SalI site right of the HIS4 PstI region was indicated erroneously on the map of HolmberG et al. (16). It should be placed $3.5 \mathrm{~kb}$ further to the right as apparent from the data given in the same paper.

As will be discussed, the finding of the cloned BamHI fragment does not mean that all 30-40 $\mathrm{kb}$ fragments detected in Figure 1 must have the same structure; most of them could have the structure of a primary product of chromosomal integration.

\subsection{Frequent lethality in strain C79-S976}

The sister chromatid recombination proposed in Figure 6 may well be expected to have lethal consequences at the following cell division. First, sequences distal to his 4 will be lost from one daughter cell and, secondly, the dicentric fragment will be in trouble, when its two centromeres move to opposite spindle poles.

Single cells of two subclones of strain C79S976 were isolated on agar slabs by micromanipulation and it was determined how many were able to form colonies. A comparison was 
Table III

Influence of integrated 2-micron DNA on the survival of single cells isolated by micromanipulation.

\begin{tabular}{lccc}
\hline Culture & $\begin{array}{c}\text { Single cells } \\
\text { isolated }\end{array}$ & $\begin{array}{c}\text { Colonies Fraction of } \\
\text { formed }\end{array}$ \\
\hline $\begin{array}{l}\text { C79-S976, } \\
\text { subclone 1 }\end{array}$ & 128 & 90 & 0.30 \\
$\begin{array}{l}\text { C79-S976, } \\
\text { subclone 2 }\end{array}$ & 72 & 57 & 0.21 \\
$\begin{array}{l}\text { C75-M23 } \\
\text { (control) }\end{array}$ & 76 & 72 & 0.05 \\
\hline
\end{tabular}

made to $\mathrm{C} 75-\mathrm{M} 23$, the strain that by transformation to $\mathrm{His}^{+}$became $\mathrm{C} 78-\mathrm{H} 23 / 1$, i.e. a strain that should be isogenic to C79-S976, except for the integrated pC504 in the latter. Table III shows that there is several-fold higher lethality in C79-S976 than in C75-M23.

\subsection{Mitotic segregation of linked genes}

One way to follow the genetic consequences of events that are lethal in a haploid is to look at the event in a diploid.

C79-S976 was crossed to C79-993 (MATa his4-644 leu2 thr4 ura4), so that the segregation of four markers on chromosome III, two on each side of the centromere, could be followed (cf. Figure 7). The resulting diploid clones segregated His $^{-}$colonies at a much higher rate than did C79. S976 (Table IV). Clone 4 is interpreted as the product of mating between the tester strain C79. 993 and a completely stabilized $\mathrm{His}^{+}$derivative of C79-S976. The high segregation rates in the first three clones suggests that the HIS4 gene is in most cases lost by an event which is lethal in a haploid, but not in a diploid. As already discussed, the sister-chromatid recombination depicted in Figure 6 is expected to be such an event. In addition to his4, other genes on chromosome III segregated, i.e. other wild type genes than

\section{his4 leu2 MAT thr4}

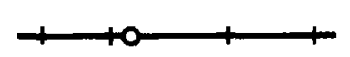

Figure 7. Map of chromosome III of S. cerevisiae. Only relevant markers are shown.
$H I S 4$, on the chromosome with the integrated 2-micron DNA, were lost. The unlinked genes ura 4 and ade 2 segregated at normal, low frequency due to mitotic crossing over and gene conversion, although, by incidence, one of the clones was Ura-. Table IV shows that $L E U 2$, which is located on the same arm as HIS4, was lost at a rate of more than $10 \%$ during the 6 generations and in more than half of the cases THR4, located on the other arm, was concomitantly lost. In order to obtain more information on the behavior of the right arm of chromosome III, some of the His ${ }^{-} \mathrm{Leu}^{-}$colonies and some of the His $\mathrm{Leu}^{+}$colonies were picked and tested for mating type. The results are given in Table $\mathrm{V}$. In most cases, when a colony was His-Leu-Thr ${ }^{+}$, it was a non-mater, whereas all His-Leu- $\mathrm{Thr}^{-}$colonies were MATa. Furthermore, all His-Leu ${ }^{+}$colonies were $\mathrm{Thr}^{+}$ and non-maters. The results of Tables IV and V can be summarized as follows: The main classes of segregants are His-Leu ${ }^{+} \mathrm{NM} \mathrm{Thr}^{+}$, $\mathrm{His}^{-} \mathrm{Leu}^{-}$ NM Thr ${ }^{+}$and $\mathrm{His}^{-} \mathrm{Leu}^{-} \mathrm{MATa} \mathrm{Thr}^{-}$. While the first class may comprise the results of several different types of events, including the excision of pC504, the most obvious interpretation of the last class is the complete loss of the chromosome which carried 2-micron DNA. The most interesting class may be the His- $\mathrm{Leu}^{-} \mathrm{NM} \mathrm{Thr}^{+}$segregants, which are still euploid, as evidenced by their non-mating phenotype. The LEU2 gene, proximal to HIS4, has been lost, while MATa and THR4 on the other arm have been retained. It raises the possibility that the dicentric fragment formed by sister-chromatid recombination (Figure 6) in the subsequent mitosis is broken into two monocentric fragments, one to each progeny cell, and that the monocentric fragments can get repaired in some way. It seemed of interest to find out whether the repair had resulted in the formation of a complete chromosome III and tetrad analysis was chosen as an obvious way to get information on this point. The two minor classes of $\mathrm{His}^{-} \mathrm{Leu}^{-} \mathrm{Thr}^{+}$colonies expressing mating type may be due to mitotic recombination.

\subsection{Tetrad analysis of subclones of the diploid containing integrated 2-micron DNA}

Several NM $\mathrm{Thr}^{+}$subclones of the clones presented in Tables IV and V were subjected to tetrad analysis. In some subclones the spore 
Table IV

Mitotic segregation of phenotypes in the diploid C79-S976 (MAT $\alpha$ HIS4 - $2 \mu-$ his4-24 ade2) $\times$ C79-993 (MATa his4-644 leu2 thr4 ura4) after 6 generations in non-selective medium.

\begin{tabular}{|c|c|c|c|c|c|c|c|}
\hline $\begin{array}{l}\text { Diploid } \\
\text { clone no. }\end{array}$ & $\begin{array}{l}\text { No. of } \\
\text { colonies }\end{array}$ & $\begin{array}{c}\mathrm{His}^{+} \mathrm{Leu}^{+} \\
\mathrm{Thr}^{+}\end{array}$ & $\begin{array}{c}\text { His-Leu }{ }^{+} \\
\mathrm{Thr}^{+}\end{array}$ & $\begin{array}{c}\text { His-Leu- }^{-} \\
\text {Thr }^{+}\end{array}$ & $\begin{array}{c}\text { His-Leu- } \\
\text { Thr }\end{array}$ & $\mathrm{Ura}^{-}$ & $\mathrm{Ade}^{-}$ \\
\hline 1 & 1284 & 129 & 1016 & 50 & 89 & 1284 & 0 \\
\hline 2 & 1663 & 166 & 1322 & 93 & 82 & 4 & 1 \\
\hline 3 & 1765 & 86 & 1402 & 96 & 181 & 3 & 0 \\
\hline 4 & 1735 & 1735 & 0 & 0 & 0 & 1 & 0 \\
\hline
\end{tabular}

viability was lower than normal, but it seemed independent of the $\mathrm{His}$ and Leu phenotypes; most importantly, none of the subclones showed a $2: 2$ segregation for viability. The analysis of three subclones of clone 1 , giving normal spore viability $(81 \%, 94 \%$ and $91 \%$, respectively) are presented in Table VI.

Subclone A is of the class, $\mathrm{His}^{-} \mathrm{Leu}^{-} \mathrm{NM} \mathrm{Thr}^{+}$, supposed to have undergone repair of a monocentric fragment. The data show that the repair resulted in a full, functional chromosome III with the constitution his4-644 leu2 MAT $\alpha$ THR4, i.e., a break of the dicentric fragment occurred between $M A T \alpha$ and LEU2. This break produced a presumably monocentric fragment which was repaired either by mitotic recombination with the homologue at the four-strand stage or by resynthesis of most of the left arm of chromosome III, using the homologue as a template.

Subclone B, of the phenotype $\mathrm{His}^{-} \mathrm{Leu}^{+} \mathrm{NM}$ $\mathrm{Thr}^{+}$, turned out to be more trivial. Here his4-24 is still present, so it can be interpreted as the product of the excision of pC504, either by loopout or by an unequal sister-chromatid exchange between a HIS4 PstI region and a his4 Pstl region. Segregants of the phenotype $\mathrm{His}^{-} \mathrm{Leu}^{+} \mathrm{NM}$
$\mathrm{Thr}^{+}$should also occur via the dicentric fragment, this being broken between LEU2 and his424 and subsequently repaired. They would give his4-644 spores only.

Subclone $C$ was like its parental clone $l$ in its mitotic segregation of $\mathrm{His}^{-}$, $\mathrm{Leu}^{-}$and $\mathrm{Thr}^{-}$. The tetrad analysis showed the presence of all three his4 alleles. The 3 asci, with his4-644 spores only, are interpreted to result from mitotic segregants in which the dicentric fragment was broken distal to $L E U 2$ and subsequently repaired. The tetrads with 2 his4-644 spores are interpreted as products of plasmid excision, leaving behind either his4-24 or HIS4.

The tetrad analyses suggest that the original cell of clone 1 , as well as that of subclone $\mathrm{C}$, had the structure HIS4 - 2-micron DNA - his4-24 at the his 4 locus and that the dicentric fragment formed in some of the cells (Figure 6) can be broken into fragments that are repaired by recombination or extensive DNA synthesis using the homologous chromosome as template.

\subsection{Fate of the acentric fragment?}

It was speculated that the acentric fragment carrying HIS4 might be able to replicate in each

\section{Table V}

Phenotypes of a sample of the histidine auxotrophic segregants presented in Table IV.

\begin{tabular}{c|ccccc|cc}
\hline $\begin{array}{c}\text { Diploid } \\
\text { clone no. }\end{array}$ & $\begin{array}{c}\text { His-Leu- colonies } \\
\text { picked }\end{array}$ & $\begin{array}{c}\text { Leu-Thr }^{+} \\
\text {NM }\end{array}$ & $\begin{array}{c}\text { Leu-Thr }^{+} \\
\text {MATa }\end{array}$ & $\begin{array}{c}\text { Leu-Thr }^{+} \\
\text {MAT } \alpha\end{array}$ & $\begin{array}{c}\text { Leu-Thr } \\
\text { MATa }\end{array}$ & $\begin{array}{c}\text { His-Leu colonies } \\
\text { picked }\end{array}$ & $\begin{array}{c}\text { Leu }^{+} \text {Thr }^{+} \\
\text {NM }\end{array}$ \\
\hline 1 & 76 & 19 & 1 & 1 & 53 & 10 & 10 \\
2 & 69 & 27 & 0 & 3 & 34 & 19 & 19 \\
3 & 87 & 29 & 3 & 0 & 52 & 59 & 59 \\
\hline
\end{tabular}


Table VI

Tetrad analysis of three subclones of the diploid C79S976 (MAT $\alpha$ HIS4 - $2 \mu$-his4-24 ade2) $\times$ C79-993 (MATa his4-644 leu2 thr4 ura4)

\begin{tabular}{|c|c|c|c|c|c|}
\hline \multicolumn{6}{|c|}{ Subclone A, phenotype His-Leu- Thr $^{+}, 13$ tetrads } \\
\hline & $4: 0$ & $3: 1$ & $2: 2$ & $1: 3$ & $0: 4$ \\
\hline his4-644/his4-24 & 13 & & & & \\
\hline LEU2/leu2 & & & & & 13 \\
\hline THR4/thr4 & & & 13 & & \\
\hline ADE2/ade2 & & & 13 & & \\
\hline$M A T a / M A T \alpha$ & & & 13 & & \\
\hline
\end{tabular}

Subclone B, phenotype His-Leu+ ${ }^{-} \mathrm{Thr}^{+}, 13$ tetrads

\begin{tabular}{|c|c|c|c|c|c|}
\hline & $4: 0$ & $3: 1$ & $2: 2$ & $1: 3$ & $0: 4$ \\
\hline his4-644/his4-24 & & & 13 & & \\
\hline LEU2/leu2 & & & 13 & & \\
\hline$T H R 4 / t h r 4$ & & & 13 & & \\
\hline$A D E 2 / a d e 2$ & & 1 & 12 & & \\
\hline$M A T \mathbf{a} / M A T \alpha$ & & & 13 & & \\
\hline \multicolumn{6}{|c|}{ Subclone C, Phenotype His ${ }^{+} \mathrm{Leu}^{+} \mathrm{Thr}^{+}, 20$ tetrads } \\
\hline & $4: 0$ & $3: 1$ & $2: 2$ & $1: 3$ & $0: 4$ \\
\hline HIS4/his4 & & 1 & $13^{a}$ & & $6^{b}$ \\
\hline LEU2/leu2 & & & 19 & 1 & \\
\hline THR4/thr4 & & & 20 & & \\
\hline ADE2/ade2 & & & 20 & & \\
\hline$M A T \mathrm{a} / M A T \alpha$ & & & 20 & & \\
\hline
\end{tabular}

a All were 2 HIS4 (stable) : 2 his4-644.

b Three tetrads were 4 his4-644:0 his4-24 and the other three were 2 his4-644: 2 his4-24.

$\mathrm{S}$ phase and that the copies might be able to disjoin more or less randomly into progeny cells. If that were the case, the acentric fragment should be maintainable by selection. To test this possibility we looked, in subclone $\mathrm{C}$ of the diploid analysed above, for cells that had lost $L E U 2$, $M A T \alpha$ and THR4, but had retained HIS4. In order to select for such cells, the experiment was carried out as a mating rescue. Thus, subclone $\mathrm{C}$ (Ura) was mated to C82-1799 (MAT $\alpha$ his4-29 leu2 thr4 trpl arg4). None of the alleles his4-29. his4-24 and his4-644 complement one another. $\mathrm{Ura}^{+} \mathrm{Trp}^{+} \mathrm{Arg}^{+} \mathrm{His}^{+}$triploids (or rather $3 \mathrm{n}-1$ ) could now be selected on minimal medium with leucine and threonine as the products of loss of $M A T \alpha$ in subclone $\mathrm{C}$ and a subsequent mating of the resulting MATa cell with a cell of C82-1799.
Most of the triploids turned out to be $\mathrm{Leu}^{-} \mathrm{Thr}^{-}$, as expected for the complete loss of the dicentric fragment. As the plate did not contain histidine, there should be a strong selection for cells with the acentric fragment carrying HIS4. The colonies were of two classes: A trivial class of large colonies with a stable $\mathrm{His}^{+}$phenotype; they were regarded as the result of gene conversion of his 4 by the HIS4 gene of the acentric fragment. The other class consisted of small colonies. Upon restreaking onto plates lacking histidine, only slight growth occurred and replica plating to new histidine-free plates gave small papillae that stopped growing. Repeated streaking yielded no growth at all, whereas streaking onto histidine-containing medium gave normal growth. Occasionally fast-growing sectors appeared in the first restreakings; they had a stable $\mathrm{His}^{+}$phenotype like the large colonies. We find it likely that the small colonies originate from cells with the acentric fragment. It is not clear why the fragment can be passed on to progeny cells for some generations and not later on. Attempts to recover the acentric fragment by its internuclear transfer in a $k a r$ cross (27) gave the same result.

\section{DISCUSSION}

As previously reported in summarized form (21), the present study shows that 2-micron DNA can integrate into a yeast chromosome if it has been joined in vitro to a sequence providing homology and that the integrated plasmid can give rise to a chromosomal rearrangement as depicted in Figure 6. We have furthermore studied the genetic consequences of having an integrated copy of 2-micron DNA in order to obtain information on the behavior of the chromosomal fragments formed.

\subsection{Chromosomal rearrangement caused by integrated 2-micron DNA}

The cloning of the BamHI insert found in pC505 is evidence for the presence of the acentric fragment in the culture and thereby for the occurrence of the rearrangement depicted in Figure 6. This evidence is supported by the finding of high lethality in C79-S976 and the segregation of chromosome III markers in the diploid C79S976 $\times$ C79-993. The rates of these events are consistent with the view that a large proportion of 
the cells of the C79-S976 culture had undergone the sister-chromatid recombination (Figure 6). It is likely that a fairly large proportion of the $30-40$ $\mathrm{kb}$ BamHI fragments which we found to contain HIS4 sequences (Figure 1) had been cut out from the acentric fragment and the dicentric fragment, but that still the majority had the simpler structure of the primary product of integration of pC504.

The rate of the unequal sister-chromatid recombination is much higher than usually found for similar mitotic events, such as uneven sisterchromatid recombination in the $R D N I$ cluster $(29,35)$ or loss of an integrated plasmid (15). We have proposed (21) that this is due to the high efficiency of the FLP promoted recombination system, specific for the inverted repeat of 2-micron DNA (3), and which we suppose also works on integrated sequences. This view has recently been confirmed by FALco et al. (9), who selected for chromosomal integration of plasmids containing either of the two repeated regions of 2micron DNA. Such an integration does not by itself allow an unequal sister-chromatid recombination, but in strains with the natural 2-micron DNA plasmid ([ $\left.\mathrm{Cir}^{+}\right]$strains), FAlco et al. (9) detected the additional integration of a full copy of 2-micron DNA into the insert. In that situation, three copies of the repeated sequence of 2 micron DNA are present in the chromosome in alternate orientation, allowing the unequal, inverted sister-chromatid recombination to take place. Only in strains with $F L P$ function did FALco et al. (9) observe the events which they interpreted as the result of the sister-chromatid recombination.

\subsection{Behavior of the dicentric fragment}

Already before the sister-chromatid recombination, in S or G2 phase, the two centromeres ending up in the dicentric chromosome must have been predestined to go to opposite poles in the following mitosis, since the chromatids of different chromosomes segregate together as a function of the generation in which they were synthesized (39). It may therefore be expected that, in every cell where the dicentric fragment is formed, the two centromeres will try to go to opposite poles. In maize endosperms this situation leads to breakage of the dicentric fragment and fusion of the broken ends after DNA replication, whereby a new dicentric fragment is formed (23). Whether this full cycle can take place in our case is unknown. We have found, however, that in the diploid, the chromosome with 2-micron DNA is frequently lost. Also, in many segregants, we observed the loss of $L E U 2$ and the subsequent repair of the chromosome into its normal structure, i.e., with no lethal deletions etc. The repair resulted in a chromosome arm containing the leu2 and his4-644 information from the homologue. We interpret this to be due to the recombinogenic effect of free ends of double-stranded DNA found by ORR-WeAVER et al. (28) in studies of plasmid integration. McCuSKER and HABER (24) have found evidence that the recombinogenic effect of a free DNA end at the $M A T$ locus can lead to the repair of chromosome III by recombination with the homologue or by copying the right arm of the homologue. FALCO et al. (9), studying the genetic effects of the integration of 2-micron DNA sequences at ura3 and leu2 have obtained effects, on those loci and on linked markers, similar to those described here. Like FALco et al., we suggest that the broken DNA end invades the homologous chromosome and uses it either for recombination or as a template for the resynthesis of the large, missing part of the chromosome. We cannot distinguish the two types of mechanism.

\subsection{Behavior of the acentric fragment}

It was not possible to maintain the acentric fragment with HIS 4 by selective growth, i.e., in the absence of histidine. It is not known why some growth on the histidine-free plates occurred after the mating designed to rescue the acentric fragment. Some replication and disjunction of a HIS4 carrying genetic element must have taken place, since each small colony could give rise to several papillae, but then growth stopped. Whether this stop was due to defective replication or increased failure of disjunction is not known. Small artificial, linear plasmids that have presumably no centromeric function are easily maintainable in yeast (34). One possible ad hoc interpretation of our results is that large chromosome fragments that do not contain a centromere can be pulled into the buds of a zygote, but not into the buds of normal vegetative cells. 


\section{ACKNOWLEDGEMENTS}

The authors are indebted to D. von WETTSTEIN, R. Egel and C. GJeRmansen for interest and discussions and to G. BANK, J.V. HANSEN and B. WILKEN for technical assistance. This work was supported by grants 511-20672, 51220779, 516-20214.H-510 and 16-1740.H-547 from the Danish National Research Councils for Natural, Medical and Technical Sciences to D. voN WETTSTEIN.

\section{REFERENCES}

1. BRANDT, A.: Cloning of double stranded DNA coding for hordein polypeptides. Carlsberg Res. Commun. 44, 255-267 (1979)

2. BROACH, J.R.: The yeast plasmid $2 \mu$ circle. In: The Molecular Biology of the Yeast Saccharomyces. Life Cycle and Inheritance. J. Strathern, E. Jones \& J. Broach, eds., Cold Spring Harbor Laboratory. Cold Spring Harbor, New York. pp. 445-470 (1981)

3. BROACH, J.R., V.R. Guarascio \& M. JaYaram: Recombination within the yeast plasmid $2 \mu$ circle is site-specific. Cell 29, 227-234 (1982)

4. Cameron, J.R., P. Philippsen \& R.W. Davis: Analysis of chromosomal integration and deletions of yeast plasmids. Nucl. Acids Res. 4, 1429- 1448 (1977)

5. Cohen, S.N., A.C.Y. Chang \& L. Hsu: Nonchromosomal antibiotic resistance in bacteria: Genetic transformation of Escherichia coli by R-Factor DNA. Proc. Nat. Acad. Sci. USA 69, 2110-2114 (1972)

6. Collins, J. \& H.J. BR Uning: Plasmids useable as gene-cloning vectors in an in vitro packaging by coliphage $\lambda$ :"Cosmids". Gene 4, 85-107 (1978)

7. Collins, J. \& B. Hohn: Cosmids: A type of plasmid gene-cloning vector that is packageable in vitro in bacteriophage $\lambda$ heads. Proc. Nat. Acad. Sci. USA 75, 4242-4246 (1978)

8. DenhardT, D.T.: A membrane-filter technique for the detection of complementary DNA. Biochem. Biophys. Res. Commun. 23, 641-646 (1966)

9. Falco, S.C., Y. Li, J.R. BroaCh \& D. BotSTEIN: Genetic properties of chromosomally integrated $2 \mu$ plasmid DNA in yeast. Cell 29 , 573-584 (1982)

10. Fink, G.R. \& C.A. Styles: Gene conversion of deletions in the HIS4 region of yeast. Genetics 77, 231-244 (1974)

11. Gerbaud, C., P. Fournier, H. Blanc, M. Aigle, H. Heslot \& M. Guerineau: High fre- quency of yeast transformation by plasmids carrying part or entire $2-\mu \mathrm{m}$ yeast plasmid. Gene 5, 233-253 (1979)

12. Grunstein, M. \& D.S. Hogness: Colony hybridization: A method for the isolation of cloned DNA's that contain a specific gene. Proc. Nat. Acad. Sci. USA 72, 3961-3965 (1975)

13. Guidelines for research involving recombinant DNA molecules. Fed. Reg. 47 (167), 3804838068 (1982)

14. Hawthorne, D.C. \& R.K. Mortimer: Chromosome mapping in Saccharomyces: Centromere-linked genes. Genetics 45, 1085-1110 (1960)

15. Hinnen, A., J.B. Hicks \& G.R. Fink: Transformation of yeast. Proc. Nat. Acad. Sci. USA 75, 1929-1933 (1978)

16. Holmberg, S., M.C. Kielland-Brandt, T. Nilsson-Tillgren \& J.G.L. Petersen: Molecular characterization of three his 4 deletion mutants in Saccharomyces cerevisiae. Carlsberg Res. Commun. 44, 283-288 (1979)

17. Holmberg, S., J.G.L. Petersen, T. NilssonTillgren \& M.C. Kielland-BrandT: Molecular characterization of a Saccharomyces plasmid containing the HIS4 gene. Carlsberg Res. Commun. 44, 269-282 (1979)

18. Jefrereys, A.J. \& R.A. Flavell: A physical map of the DNA regions flanking the rabbit $\beta$ globin gene. Cell 12, 429-439 (1977)

19. Katz, L., D.T. Kingsbury \& D.R. HelinskI: Stimulation by cyclic adenosine monophosphate of plasmid deoxyribonucleic acid replication and catabolite repression of the plasmid deoxyribonucleic acid-protein relaxation complex. J. Bacteriol. 114, 577-591 (1973)

20. Kielland-Brand, M.C., T. NilssonTillgren, S. Holmberg, J.G.L. Petersen \& B.A. Svenningsen: Transformation of yeast without the use of foreign DNA. Carlsberg Res. Commun. 44, 77-87 (1979)

21. Kielland-Brand, M.C., T. NilsSonTillgren, J.G.L. Petersen \& S. Holmberg: Transformation in yeast without the involvement of bacterial plasmids. In: Molecular Genetics in Yeast. Alfred Benzon Symposium 16. D. von Wettstein, J. Friis, M. Kielland-Brandt, A. Stenderup eds., Munksgaard. Copenhagen, pp. 369-382 (1981)

22. Kielland-Brandt, M.C., B. Wilken, S. Holmberg, J.G.L. Petersen \& T. NilssonTillgren: Genetic evidence for nuclear location of 2-micron DNA in yeast. Carlsberg Res. Commun. 45, 119-124 (1980) 
23. MCClintock, B.: The behavior in successive nuclear divisions of a chromosome broken at meiosis. Proc. Nat. Acad. Sci. USA 25, 405-416 (1939)

24. MCCUSKER, J.H. \& J.E. HABER: Evidence of chromosomal breaks near the mating-type locus of Saccharomyces cerevisiae that accompany $M A T \alpha \times M A T \alpha$ matings. Genetics 99 , 383-403 (1981)

25. Nelson, R.G. \& W.L. Fangman: Nucleosome organization of the yeast $2-\mu \mathrm{m}$ DNA plasmid : A eukaryotic minichromosome. Proc. Nat. Acad. Sci. USA 76, 6515-6519 (1979)

26. Nilsson-TillgRen, T. \& A. KaHN (manuscript in preparation)

27. Nilsson-Tillgren, T., J.G.L. Petersen, S. Holmberg \& M.C. Kielland-Brandt: Transfer of chromosome III during kar mediated cytoduction in yeast. Carlsberg Res. Commun. 45, 113-117 (1980)

28. OrR-Weaver, T.L., J.W. Szostak \& R.J. RoTHSTEIN: Yeast transformation: A model system for the study of recombination. Proc. Nat. Acad. Sci. USA 78, 6354-6358 (1981)

29. Petes, T.D.: Unequal meiotic recombination within tandem arrays of yeast ribosomal DNA genes. Cell 19, 765-774 (1980)

30. Rigby, P.W.J., M. Dieckmann, C. Rhodes \& P. BERG: Labeling deoxyribonucleic acid to high specific activity in vitro by nick translation with DNA polymerase I. J. Mol. Biol. 113, 237-251 (1977)

31. Seligy, V.L., D.Y. Thomas \& B.L.A. Miki: Saccharomyces cerevisiae plasmid, Scp or 2 $\mu \mathrm{m}$ : intracellular distribution. stability and nucleosomal-like packaging. Nucl. Acids Res. 8, 3371-3391 (1980)

32. Sigurdson, D.C., M.E. GaARder \& D.M. LIVINGSTON: Characterization of the transmission during cytoductant formation of the $2 \mu \mathrm{m}$ DNA plasmid from Saccharomyces. Mol. Gen. Genet. 183, 59-65 (1981)

33. Southern, E.M.: Detection of specific sequences among DNA fragments separated by gel electrophoresis. J. Mol. Biol. 98, 503-517 (1975)

34. Szostak, J.W. \& E.H. Blackburn: Cloning yeast telomeres on linear plasmid vectors. Cell 29, 245-255 (1982)

35. SzostaK, J.W. \& R. Wu: Unequal crossing over in the ribosomal DNA of Saccharomyces cerevisiae. Nature 284, 426-430 (1980)

36. TaвaK, H.F. \& R.A. Flavell: A method for the recovery of DNA from agarose gels. Nucl. Acids Res. 5, 2321-2332 (1978)

37. TAKeto, M., S.M. JazWInSKi \& G.M. EdelMAN: Association of the 2- $\mu \mathrm{m}$ DNA plasmid with yeast folded chromosomes. Proc. Nat. Acad. Sci. USA 77, 3144-3148 (1980)

38. Weissmann, C. \& W. Boll: Reduction of possible hazards in the preparation of recombinant plasmid DNA. Nature 261, 428-429 (1976)

39. Williamson, D.H. \& D.J. Fennell: Non-random assortment of sister chromatids in yeast mitosis. In: Molecular Genetics in Yeast. Alfred Benzon Symposium 16. D. von Wettstein, J. Friis, M. Kielland-Brandt, A. Stenderup eds., Munksgaard. Copenhagen, pp. 89-102 (1981) 